Kwang-Jun Paik

http://dx.doi.org/10.21278/brod68108

ISSN 0007-215X

eISSN 1845-5859

\title{
NUMERICAL STUDY ON THE WAKE EVOLUTION OF CONTRA-ROTATING PROPELLER IN PROPELLER OPEN WATER AND SELF-PROPULSION CONDITIONS
}

UDC 629.5.035.5

Original scientific paper

\begin{abstract}
Summary
In this study, the wake characteristics of a contra-rotating propeller (CRP) were investigated using a numerical simulation. The numerical simulation was carried out with a Reynolds averaged Navier-Stokes equations solver. The numerical simulations were performed on CRPs in both propeller open water and self-propulsion conditions to investigate their wake evolution characteristics. To study the effect of the rudder on the wake in the selfpropulsion condition, the numerical simulations with and without a rudder were compared. The evolution of the CRP wake was analysed through velocity and vorticity contours on one transverse plane between the forward and aft propellers and two transverse planes located downstream of the CRP. The variations of thrust and torque of the forward and aft propellers during one revolution of the CRP were compared to investigate the interaction between forward and aft propellers and the effect of a rudder.
\end{abstract}

Key words: $\quad$ contra-rotating propeller (CRP); propeller wake; wake evolution; computational fluid dynamics (CFD); propeller-rudder interaction

\section{Introduction}

Reducing fuel consumption has always been a high priority for ship owners and ship operators. Therefore, shipyards are also making efforts to develop new devices to reduce hull resistance and improve propulsive efficiency. Recently, the regulations of International Maritime Organization (IMO) requiring the control of $\mathrm{CO}_{2}$ emission with the Energy Efficiency Design Index (EEDI) have exaggerated the requirement of the development of energy saving devices. As a result, many types of energy saving devices have been suggested, and some were applied to real ships. There is no doubt that one of the most effective devices applied to real ships to improve the propulsive efficiency is the contra-rotating propeller (CRP), even though there are still some limitations in its application to all types of vessels because of large engine room space and high initial investment costs. 
The fundamental approach to understanding the characteristics of propeller operation is the investigation of the evolution of propeller wake. The wake evolution was studied by an experimental measurement and a numerical simulation. The experimental measurement was performed with a pitot tube or a laser Doppler velocimetry (LDV) [1, 2], but most recent wake measurements were carried out using a particle image velocimetry (PIV). Tukker et al. [3] and Felli et al. [4] showed the availability of PIV to measure propeller wake. Di Felice et al. [5] examined the characteristics of propeller wake evolution at different loading conditions. Paik et al. [6] investigated the characteristics of the tip vortex and trailing vortex of a propeller. The mechanisms of the evolution of propeller wake in the transition and far fields were researched by Felli et al. [7]. The propeller wake field according to the variation of the propeller phase angle was studied by Hwang et al. [8]. Felli et al. [9] measured wake field and pressure fluctuation downstream of the propeller to investigate the correlation of the velocity and pressure signal. On the other hand, numerical simulations using computational fluid dynamics (CFD) based on Reynolds averaged Navier-Stokes (RANS) equations were performed by Rhee and Joshi [10], Di Felice et al. [11], Arikan et al. [12], Wang and Walters [13], Baek et al. [14], and Kinaci and Gokce [15] to study the characteristics of propeller wake.

Numerical methods based on potential theory have been applied to study the characteristics of CRP wake for a long time (Tsakonas et al. [16], Hoshino [17], and Paik et al. [18]). However, Paik et al. [19] applied CFD based on the RANS equations to investigate the characteristics of wake as well as shaft forces according to the combination of number of blades for the forward and aft propellers of CRPs. Paik et al. [20] performed PIV measurements and CFD simulations to survey the wake field of CRPs in detail.

In this research, a numerical investigation was performed to study the wake evolution of a CRP in propeller open water (POW) and self-propulsion conditions. The evolution of CRP wake was analysed through velocity and vorticity contours on one transverse plane between the forward and aft propellers and two transverse planes located downstream of the CRP. To study the wake effect of a rudder in the self-propulsion condition, the numerical simulations were compared with and without a rudder. And the variations of thrust and torque during one revolution were compared to investigate the interactions between the forward and aft propeller and between the CRP and the rudder.

\section{Method of numerical simulation}

\subsection{Numerical models}

A numerical simulation was performed using a commercial CFD code (FLUENT ver. 14) based on RANS equations. The governing equations for the conservations of mass and momentum are described as follows:

$$
\begin{aligned}
& \frac{\partial \rho}{\partial t}+\nabla \cdot(\rho \vec{u})=0 \\
& \frac{\partial}{\partial t}(\rho \vec{u})+\nabla \cdot(\rho \vec{u} \vec{u})=-\nabla p+\nabla \cdot \bar{\tau}+\rho \vec{g}
\end{aligned}
$$

The stress tensor $\overline{\bar{\tau}}$ is given by

$$
\bar{\tau}=\mu\left[\left(\nabla \vec{u}+\nabla \vec{u}^{T}\right)-\frac{2}{3} \nabla \cdot \vec{u} I\right]
$$

where $\mu$ is the molecular viscosity and $I$ is the unit vector. 
The numerical method applied for the turbulence model was the Reynolds stress model (RSM), and pressure and velocity were coupled with the SIMPLEC (Semi-Implicit Method for Pressure Linked Equations-Consistent) algorithm. The applied numerical methods were previously verified by Paik et al. [20].

\subsection{Simulation setup}

The main particulars of the object ship, a 70K Product Carrier, used in this study are summarized in Table 1. The scale ratio of the model ship is 32.7273. The number of blades is four for both propellers. The diameter of the aft propeller is $88.9 \%$ of the forward propeller diameter. The CRP was designed to maximize propulsive efficiency using backward rake for forward propeller and forward rake for aft propeller, which was proposed by Inukai [21]. The main particulars of the CRP are summarized in Table 2.

Table 1 Main particulars of 70K PC

\begin{tabular}{|c|c|}
\hline LBP $(\mathrm{m})$ & 219.0 \\
\hline Breadth $(\mathrm{m})$ & 32.2 \\
\hline Draught $(\mathrm{m})$ & 12.2 \\
\hline
\end{tabular}

Table 2 Main particulars of CRP

\begin{tabular}{|c|c|c|}
\hline & Forward propeller & Aft propeller \\
\hline Diameter $(\mathrm{m})$ & 7.2 & 6.4 \\
\hline Number of blades & 4 & 4 \\
\hline P/D @ 0.7 r/R & 0.739 & 0.882 \\
\hline C/D @ 0.7 r/R & 0.210 & 0.204 \\
\hline Rotation direction & Counter-clockwise & Clockwise \\
\hline
\end{tabular}

The grid system for the POW condition as shown in Figures 1 and 2 has two sliding blocks for the forward and after propellers. Pyramid cells were used on the surface of the propeller blade and the boundary of the sliding blocks, and tetrahedral cells were filled inside the sliding block. Except for the sliding blocks, structure girds were employed in the other domains.

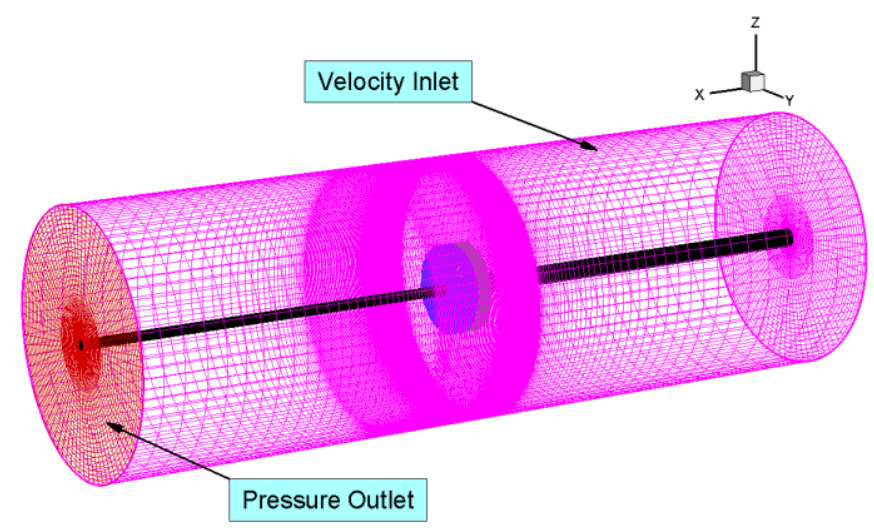

Fig. 1 Computational domain and boundary conditions for POW condition 


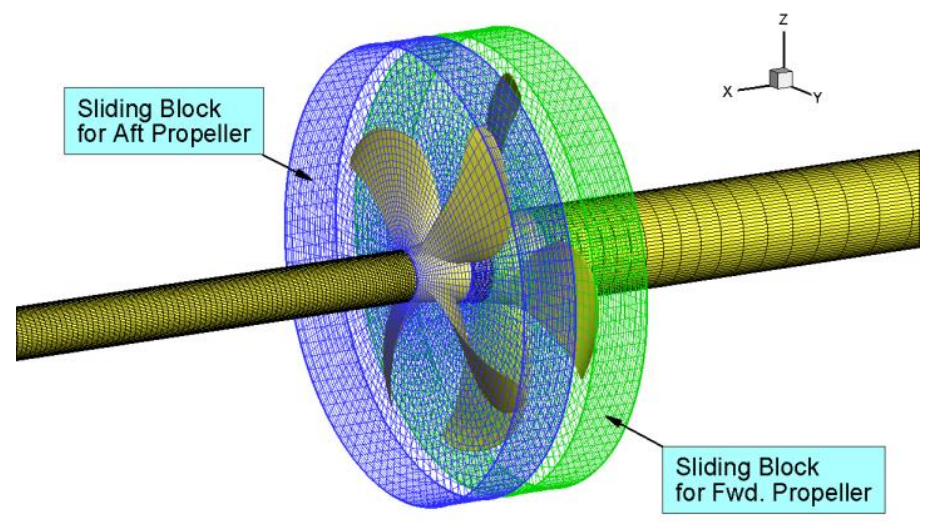

Fig. 2 Sliding blocks for forward and aft propellers

The computational domain and boundary conditions for the self-propulsion condition are illustrated in Figure 3. Two sliding blocks were applied to simulate the rotation of forward and aft propellers as shown Figure 4. Several multi-blocks were applied for the wake region of the CRP and the gap between the forward and aft propellers as shown in Figures 5.

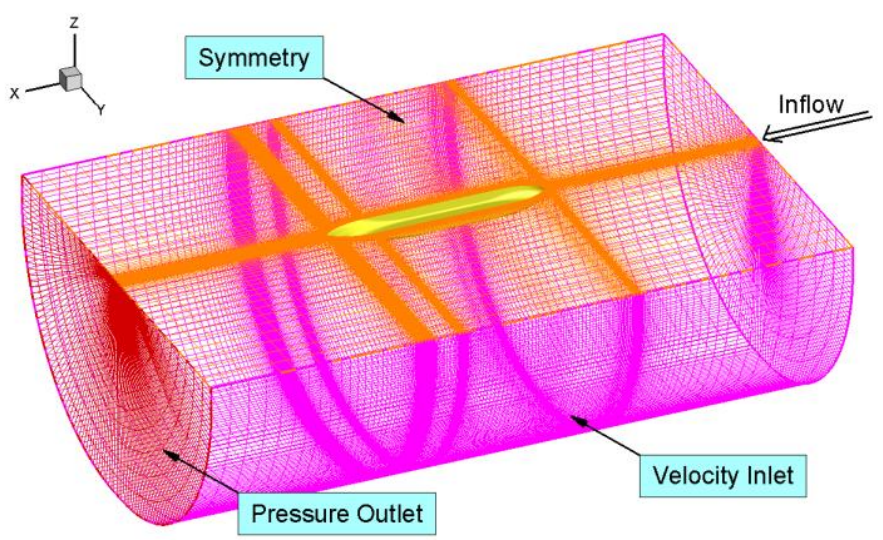

Fig. 3 Computational domain and boundary conditions for self-propulsion condition

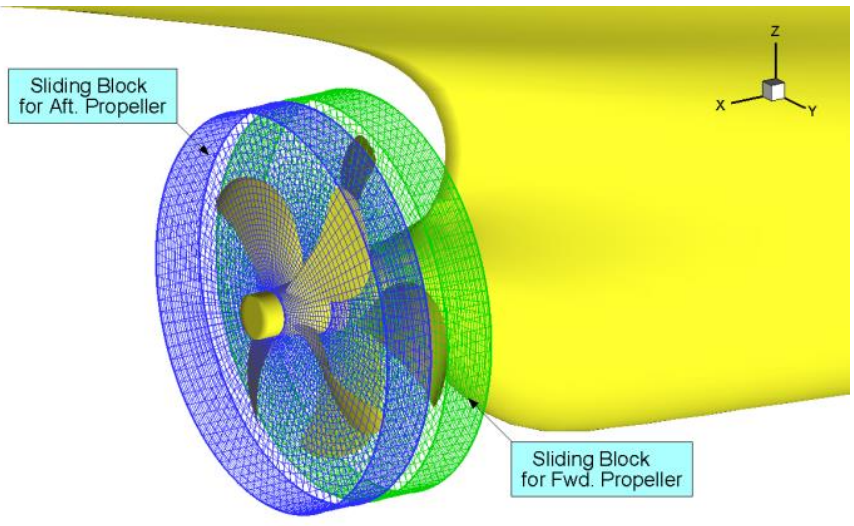

Fig. 4 Grid structure of sliding blocks for forward and aft propellers. 


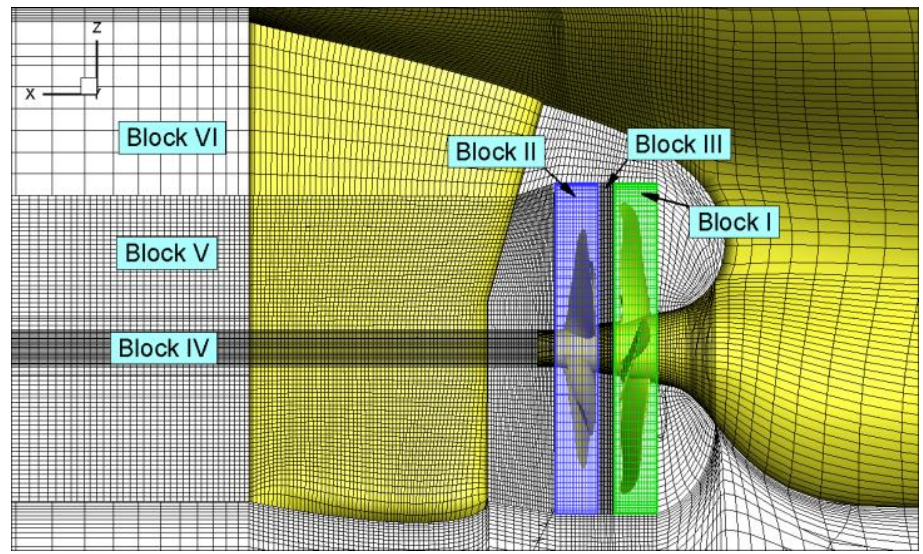

Fig. 5 Multi-block structures for self-propulsion conditions with a rudder

The numbers of grids for the blocks of the forward and aft propellers are about $599 \mathrm{~K}$ and $595 \mathrm{~K}$, respectively. The total number of grids for the POW and self-propulsion conditions are approximately $2 \mathrm{M}$ and $3 \mathrm{M}$, respectively, as summarized in Table 3.

Table 3 Number of grid cells for simulations

\begin{tabular}{|c|c|c|c|}
\hline & POW & $\begin{array}{c}\text { Self-propulsion } \\
\text { w/o rudder }\end{array}$ & $\begin{array}{c}\text { Self-propulsion } \\
\text { w/ rudder }\end{array}$ \\
\hline Block I & \multicolumn{3}{|c|}{$599 \mathrm{~K}$} \\
\hline Block II & \multicolumn{3}{|c|}{$595 \mathrm{~K}$} \\
\hline Others & $634 \mathrm{~K}$ & $1,793 \mathrm{~K}$ & $1,961 \mathrm{~K}$ \\
\hline Total & $1,798 \mathrm{~K}$ & $2,957 \mathrm{~K}$ & $3,125 \mathrm{~K}$ \\
\hline
\end{tabular}

Initially, the forward and aft propellers were installed with a phase angle difference of $45^{\circ}$ as depicted in Figure 6. The blades are numbered according to the rotating direction of the propeller. " $F$ " in the name of the blade stands for the forward propeller, and " $A$ " stands for the aft propeller. The definition of propeller blade angle $(\theta)$ follows the rotational direction of the forward propeller.

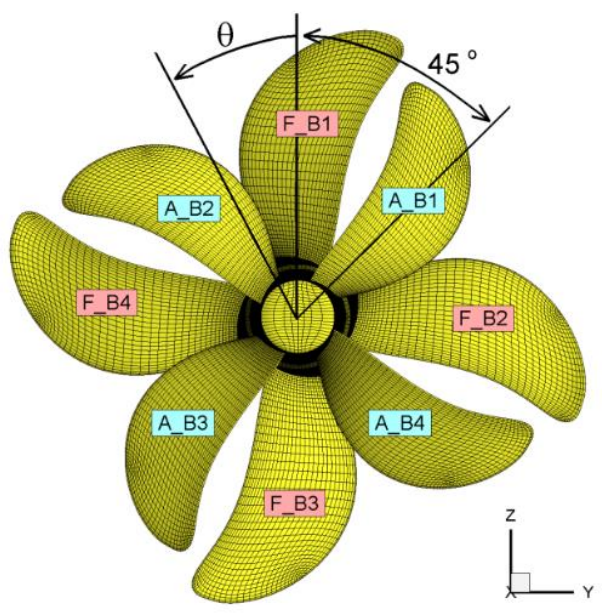

Fig. 6 Blade position and notation of forward and aft propellers (looking upstream) 
The rotational speeds of the forward and aft propellers were identical. In the POW condition, the inflow velocity was $2.709 \mathrm{~m} / \mathrm{s}$ and the rotational speed of the forward and aft propellers was $15.0 \mathrm{rps}$. The inflow velocity and the rotational speed of the CRP in the selfpropulsion conditions were $1.349 \mathrm{~m} / \mathrm{s}$ and $7.47 \mathrm{rps}$, respectively. The apparent advance coefficients $(J)$ of the forward and aft propellers for the POW and self-propulsion conditions were 0.821 and 0.923 , respectively. The operation condition was the self-propulsion point estimated from a model test in a towing tank. The propellers rotated with a constant time step corresponding to the rotation angle of $1.5^{\circ}$ to obtain 240 data during each revolution for the both conditions. The wake field was investigated at three positions in the propeller downstream as defined in Figure 7. The reference position is the after perpendicular (AP), and the three positions are defined as positions $\mathrm{A}, \mathrm{B}$, and $\mathrm{C}$, which are located at $146.6 \mathrm{~mm}, 103.0 \mathrm{~mm}$, and $66.1 \mathrm{~mm}$ from the AP, respectively.

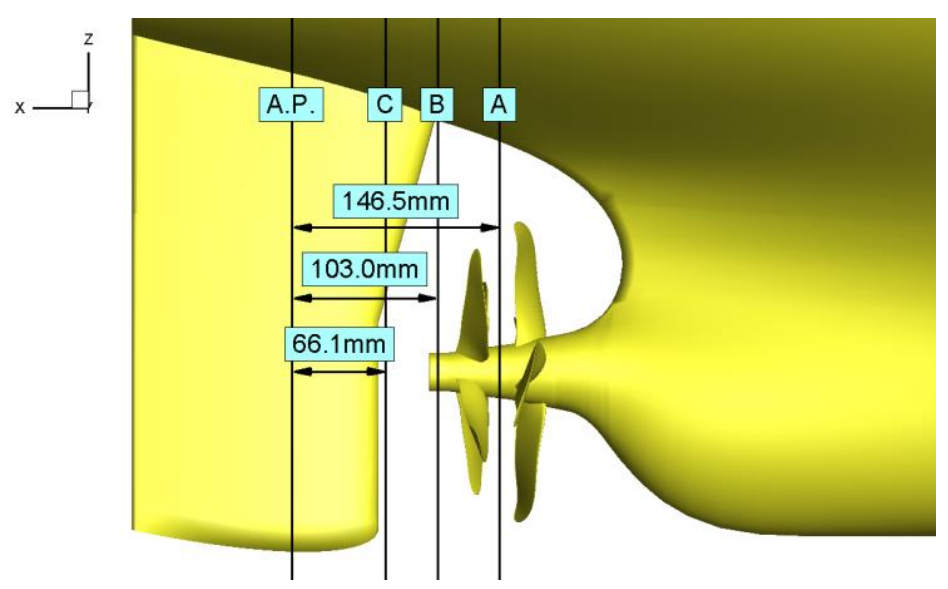

Fig. 7 Positions for wake field investigation

\section{Results and discussion}

\subsection{Propeller open water condition}

The iso-surfaces of axial vorticity in the POW condition are shown in Figure 8. For the tip vortex, the blue colour is the vortex of the forward propeller and the red colour is that of the aft propeller. For the root vortex, the blue colour is for the aft propeller and the red colour is for the forward propeller. The tip vortex of the forward propeller are clearly observed. The interaction between the tip vortices of the forward and aft propellers is not strong because the diameter of the aft propeller is about $89 \%$ of the forward propeller. The root vortex of the forward propeller disappears owing to the interaction with the aft propeller. On the other hand, the root vortex of the aft propeller extends downstream. The shed vortex of the aft propeller is also observed, while that of the forward propeller is not observed.

The variations of thrust and torque of the forward and aft propellers are compared during one revolution in Figure 9. They have eight peaks, which is twice the number of blades, owing to the interaction of the two propellers. The mean thrust of the forward propeller is higher than that of the aft propeller because the CRP was designed to distribute 55\% and $45 \%$ of total power for the forward and aft propellers in the self-propulsion condition, respectively. The amplitude of variation of the forward propeller is greater than that of the aft propeller, which is the same tendency as Paik et al. [19]. 

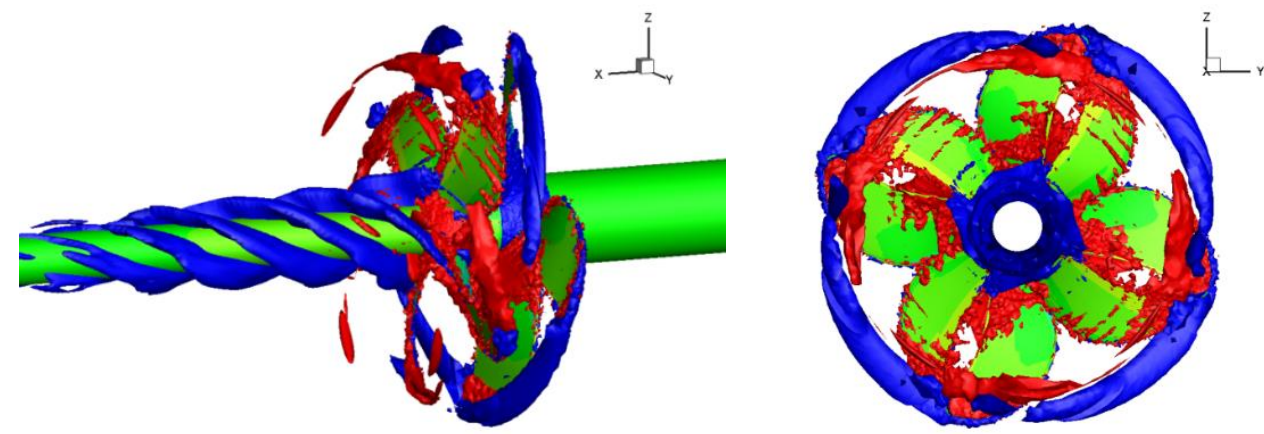

Fig. 8 Iso-surfaces for axial vorticity $\left(\omega_{x}= \pm 30\right)$ at POW condition (left: oblique view, right: rear view)

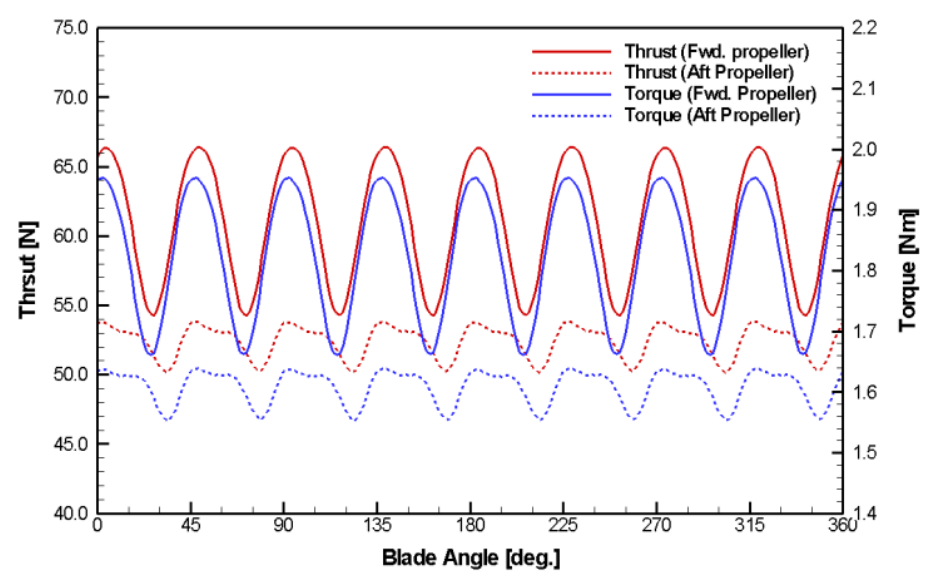

Fig. 9 Comparison of thrust and torque variations of CRP at POW condition

The velocity contours and vectors are compared at positions A, B, and C in Figure 10. The dotted circle in the figure denotes the propeller disk of the forward propeller and the view looks upstream. The strong counter-clockwise rotational component in the time-average velocity vectors observed at position $A$ is due to the forward propeller operation, whereas the rotational component at positions $\mathrm{B}$ and $\mathrm{C}$ is mitigated owing to the interaction with the aft propeller. This explains the principals of the reduction of the rotational energy loss in the CRP. Instantaneous velocity contours $\left(\theta=0^{\circ}\right)$ at position A shows the interaction with the aft propeller with four isolated velocity contours. These isolated velocity contours make the thrust and torque of the forward and aft propellers fluctuating with eight peaks as shown in Figure 9. The characteristics of the wake according to the position can be explained more clearly with instantaneous axial vorticity distribution. A propeller blade and its tip vortex (F_B1_TV, F_B4_TV) of the forward propeller at position A have a phase angle difference of about $45^{\circ}$ owing to the effect of the propeller pitch. The tip vortices (F_B1_TV, F_B4_TV) of the forward propeller almost disappear at position B, whereas the tip vortices (A_B1_TV, A_B4_TV) of the aft propeller are observed. The shape of the shed vortex (A_B4_SV) connecting between the root vortex (A_B4_RV) and the tip vortex (A_B4_TV) of the aft propeller at position B is more noticeable than that of the forward propeller at position $\mathrm{A}$. The axial velocity around the tip vortex (A_B1_TV, A_B4_TV) of the aft propeller at position B is accelerated at position C, whereas the tip vortex of the aft propeller at position $\mathrm{B}$ is weakened at position $\mathrm{C}$. As shown in Figure 8, the root vortex (A_B1_RV, A_B4_RV) of the aft propeller at position C remains, while the root vortex (F_B1_RV, F_B4_RV) of the forward propeller disappears. 

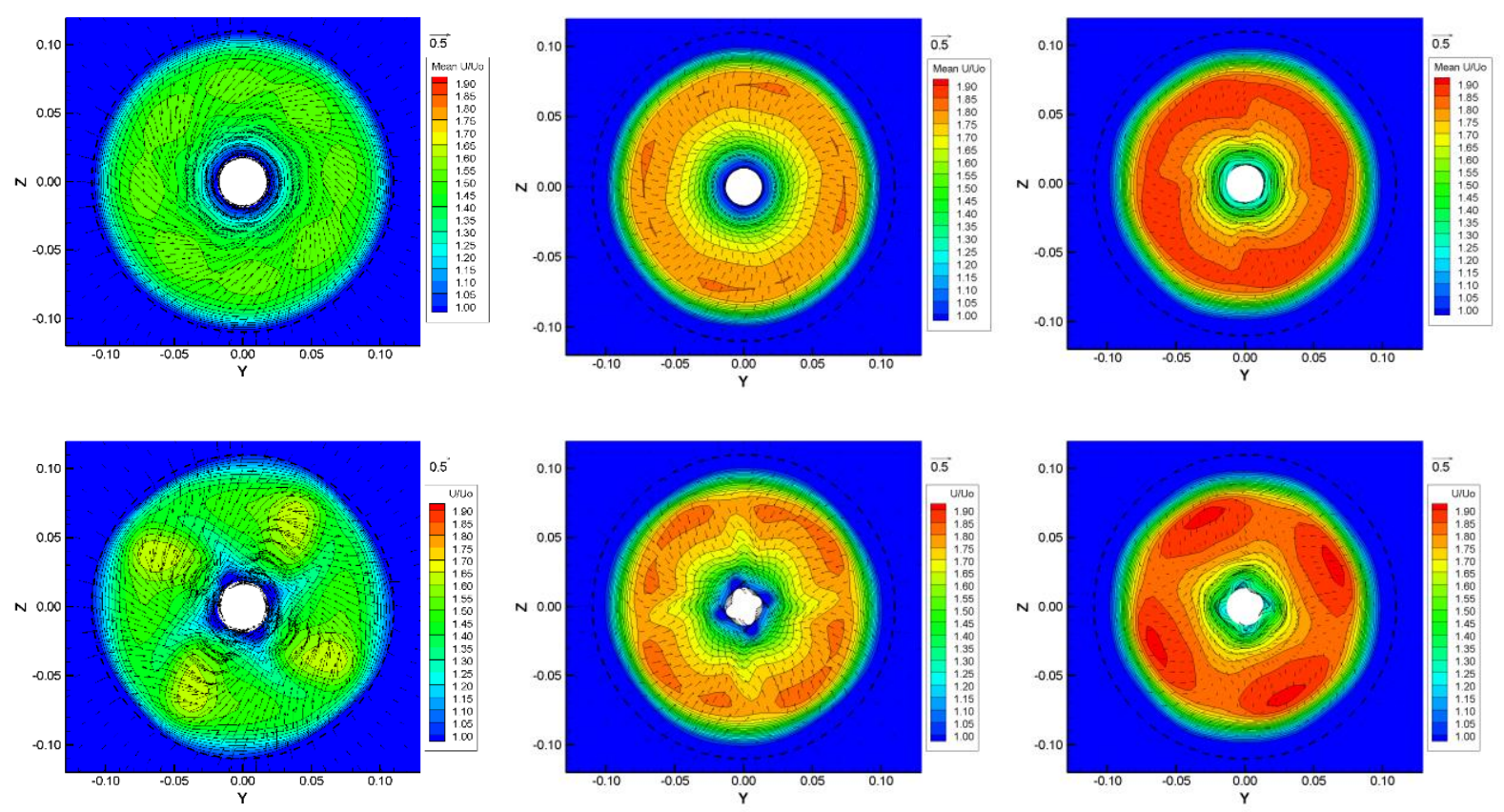

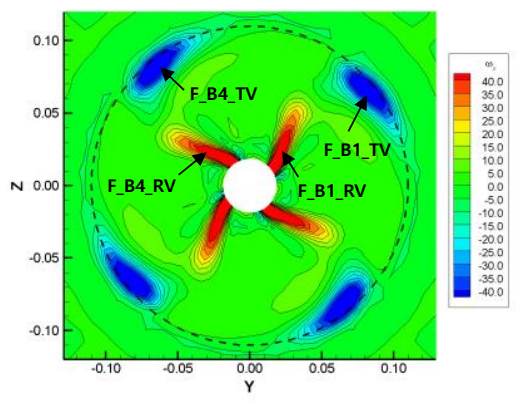

(a) Position A

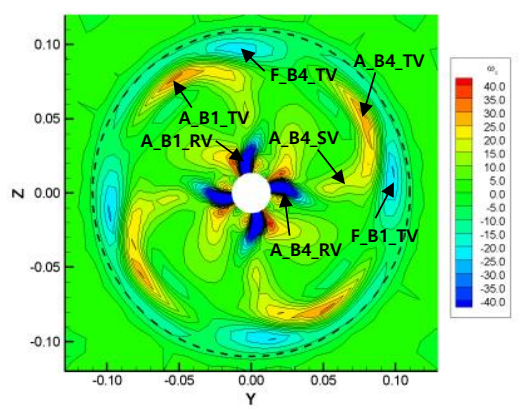

(b) Position B

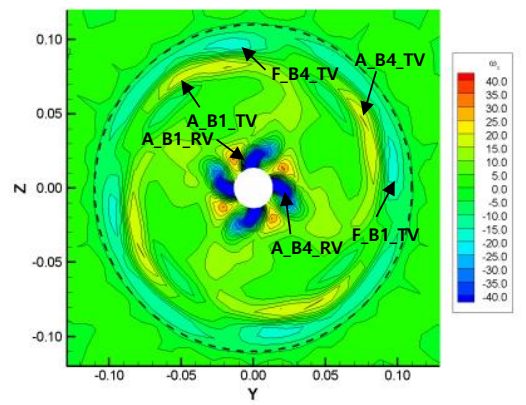

(c) Position C

Fig. 10 Time-averaged velocity contours and vectors (top), instantaneous ( $\left.\theta=0^{\circ}\right)$ velocity contours and vectors (middle), and axial vorticity contours (bottom) at positions $\mathrm{A}, \mathrm{B}$, and $\mathrm{C}$

\subsection{Self-propulsion condition}

The effect of a rudder on the wake evolution of the CRP was studied at self-propulsion condition. The iso-surface of the axial vorticity of the cases with and without a rudder are compared and shown in Figure 11. The root vortices in the case with a rudder is slightly larger due to the interaction with the rudder, and a strong negative vortex (WSV, wake shear vortex), generated by crossing flow of the rotational components in hull wake and propeller swirl, observed on the top of propeller disappears due to the rudder. The root vortex (red) of the forward propeller is biased to the starboard side because the loading of the forward propeller at the starboard side is greater than that of the port side due to the tangential component of hull wake. However, the root vortex (blue) of the aft propeller balances well since the rotational component of hull wake is mitigated due to the forward propeller. Nevertheless, there is no significant difference in the vortex structures around the propellers for the both cases.

The thrust and torque in the case with a rudder are greater compared to that of the case without a rudder as illustrated in Figure 12. The increase of thrust and torque is due to the reflection effect of the rudder. The thrust increments of the forward and aft propellers due to the rudder are about $10.3 \%$ and $3.5 \%$, respectively. And the torque increments of the forward 
and aft propellers are about $6.8 \%$ and $4.7 \%$, respectively. As a result, the propulsive efficiency of the forward propeller is increased, whereas that of the aft propeller is decreased.
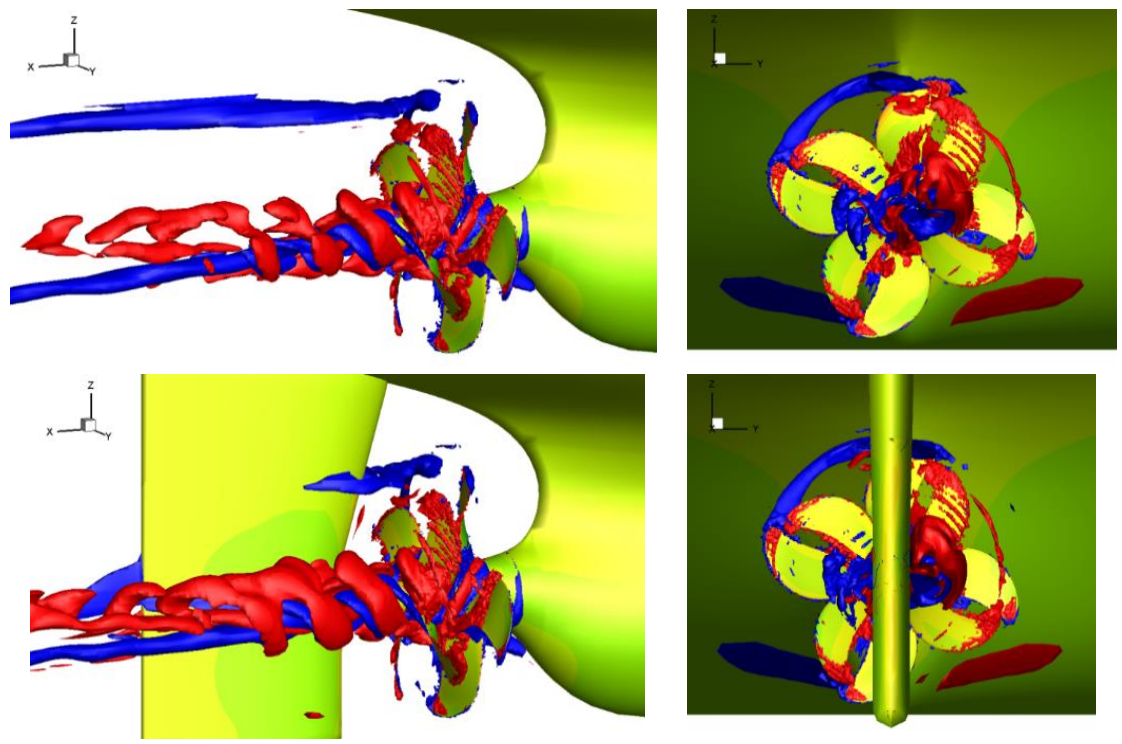

Fig. 11 Comparison of iso-surface for axial vorticity between without (top) and with (bottom) rudder for selfpropulsion condition $\left(\omega_{x}= \pm 30\right)$
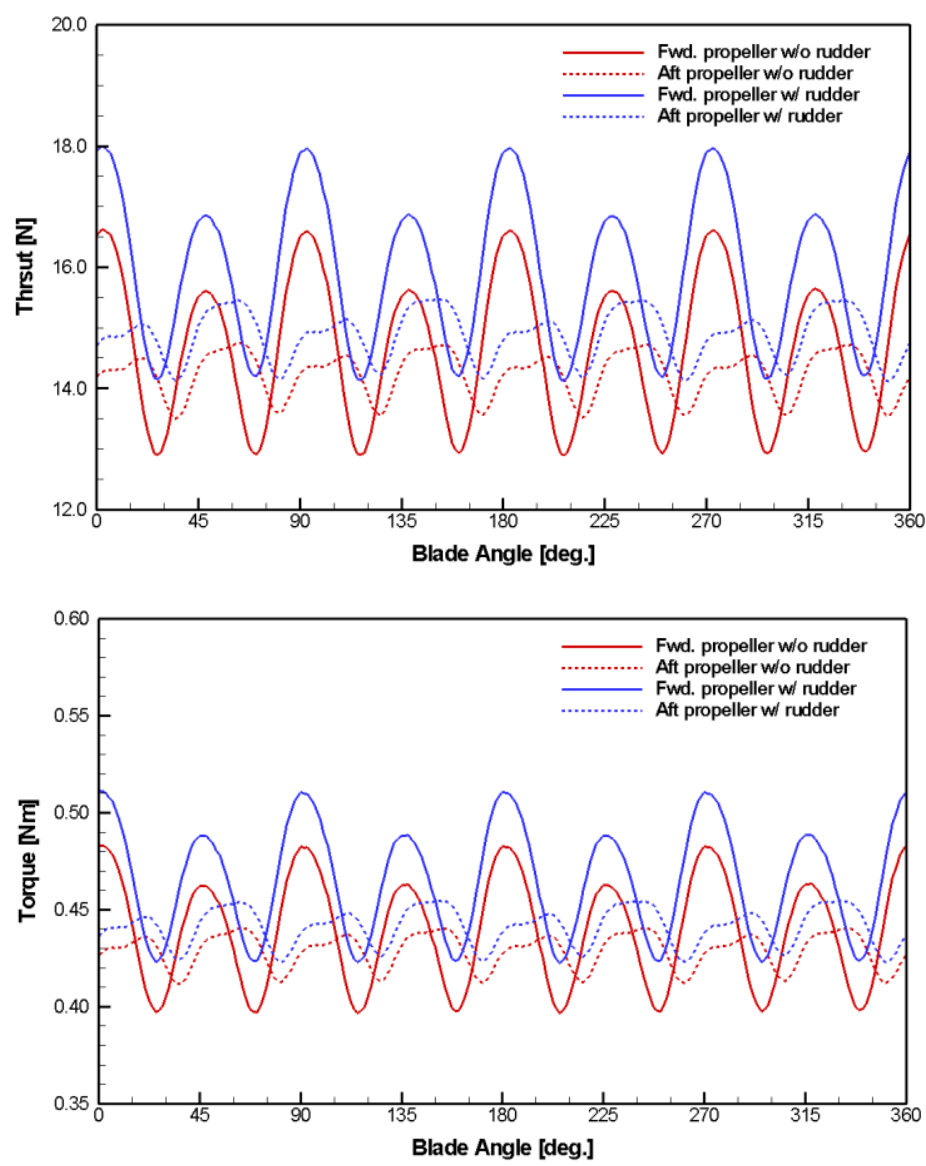

Fig. 12 Comparison of thrust (top) and torque (bottom) 
The FFT analysis results of the thrust and torque are compared in Figure 13 for the cases with and without a rudder. In general, the amplitudes in even blade frequencies are greater than those in odd blade frequencies. Strasberg \& Breslin [22] suggested Equations 4 and 5 to find the dominant frequencies of the axial and transversal fluctuating forces due to the interaction between the forward and aft propellers.

$$
\begin{aligned}
& f=m Z_{f} N_{f}+n Z_{a} N_{a} \\
& f^{\prime}=m^{\prime} Z_{f} N_{f}+n^{\prime} Z_{a} N_{a}
\end{aligned}
$$

where $f$ and $f^{\prime}$ are the dominant frequencies for the axial and transversal forces, respectively. $Z$ and $N$ are the number of blades and the rotational speed of a propeller. Subscript $f$ and $a$ denote the forward and aft propellers, respectively. $m$ and $n$ are the natural numbers to satisfy the relation of $m Z_{f}=n Z_{a}$, and $m^{\prime}$ and $n^{\prime}$ are the natural numbers to satisfy the relation of $m^{\prime} Z_{f} \pm 1=n^{\prime} Z_{a}$. In other words, the $2^{\text {nd }}$ and $4^{\text {th }}$ order blade frequencies correspond to $m=n=1$ and $m=n=2$, and they are the dominant frequencies of thrust and torque variations. On the other hand, the $1^{\text {st }}$ order blade frequency reflects the effect of hull wake rather than the transversal forces. The amplitude of the $1^{\text {st }}$ order blade frequency for the case with a rudder increases slightly owing to the effect of the rudder, whereas the changes in the other frequencies are not distinct.

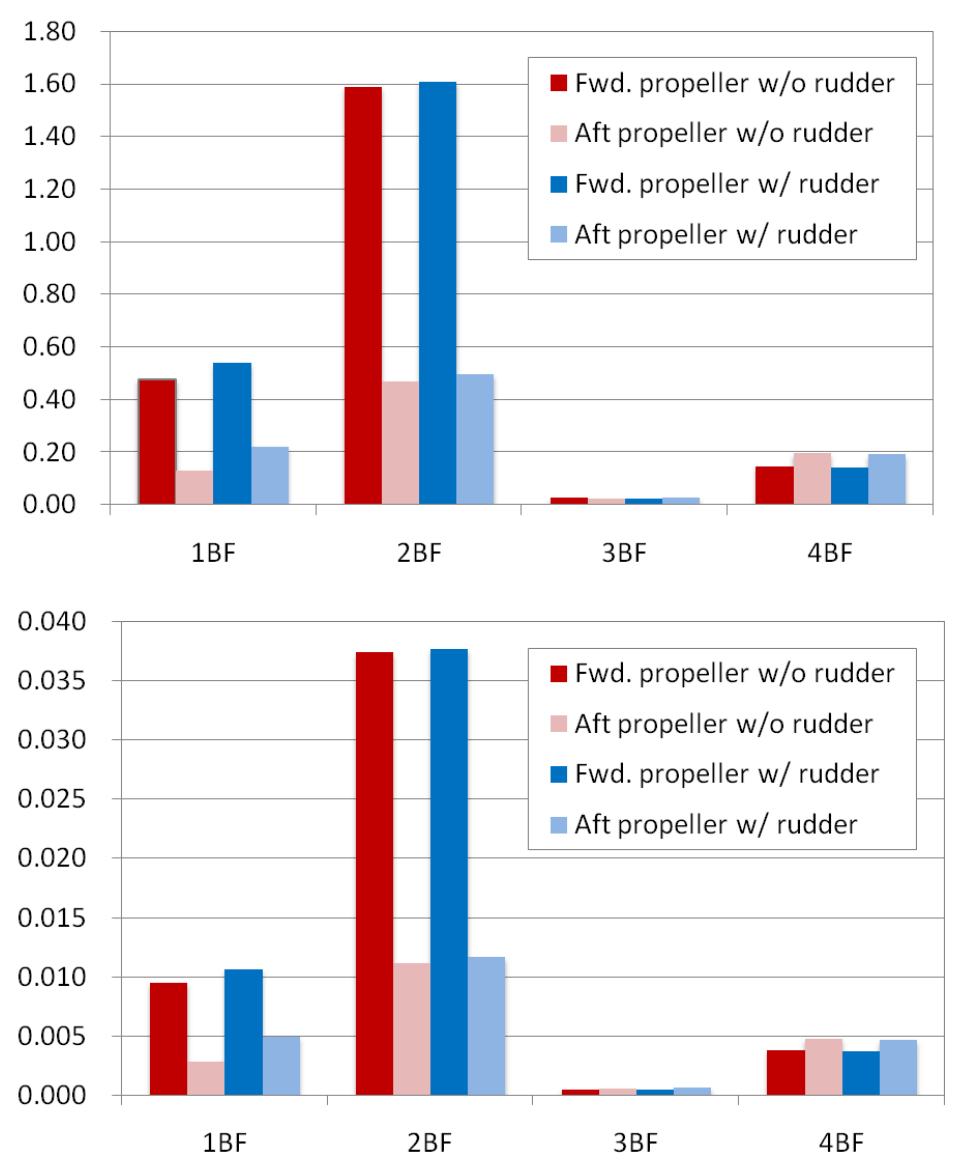

Fig. 13 FFT results of thrust (top) and torque (bottom) for the cases with and without rudder 

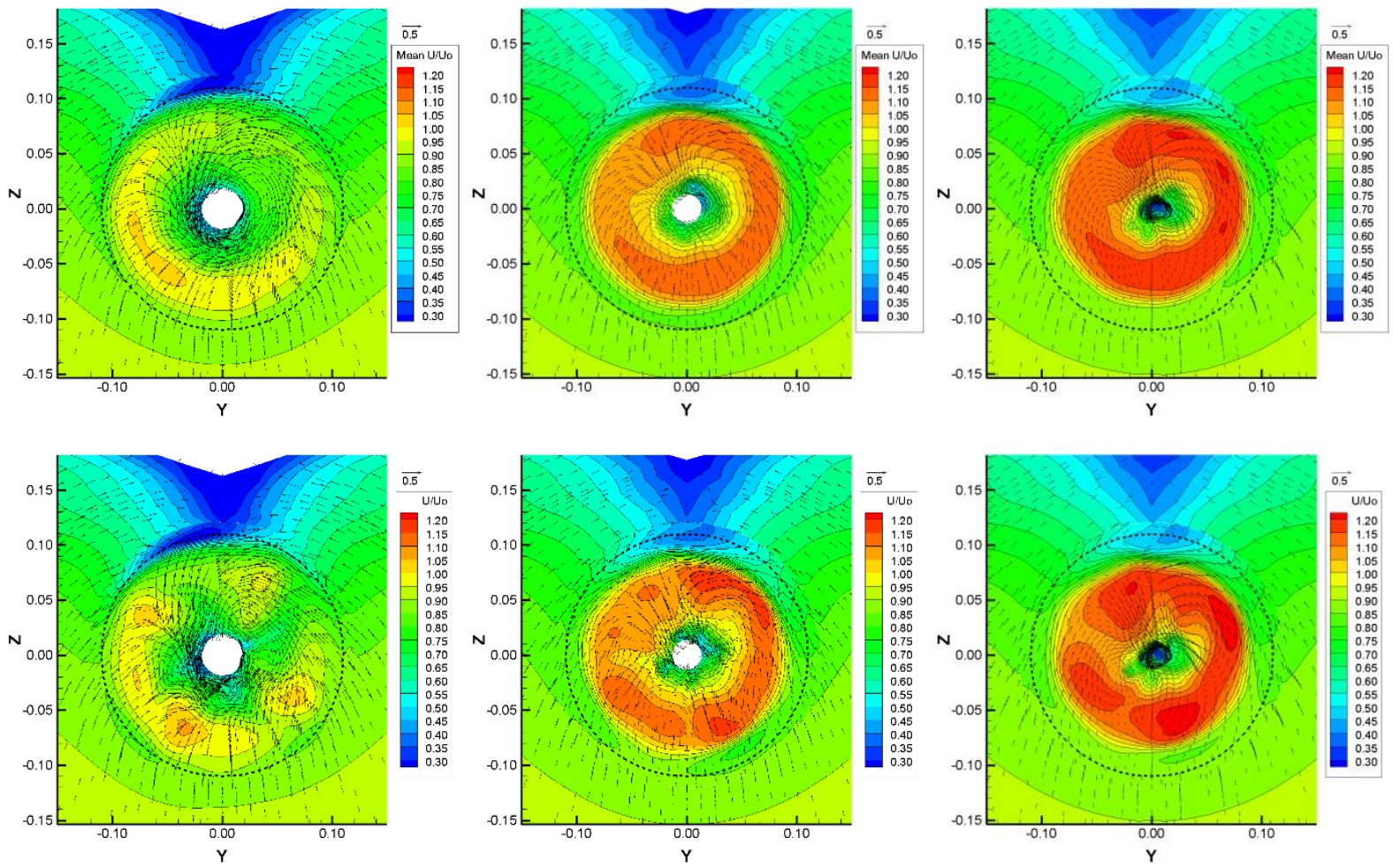

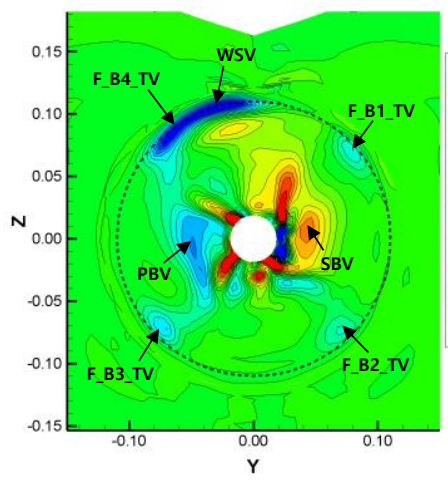

(a) Position A
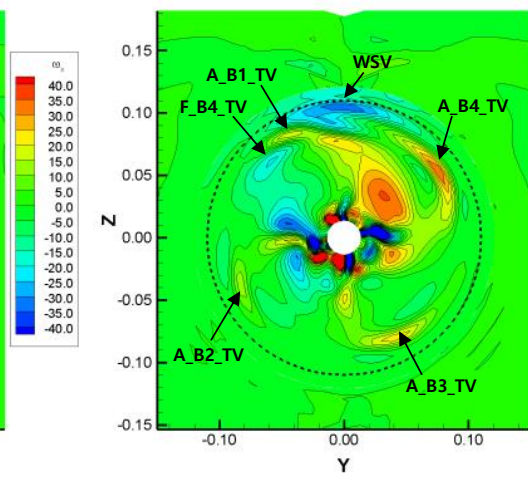

(b) Position B
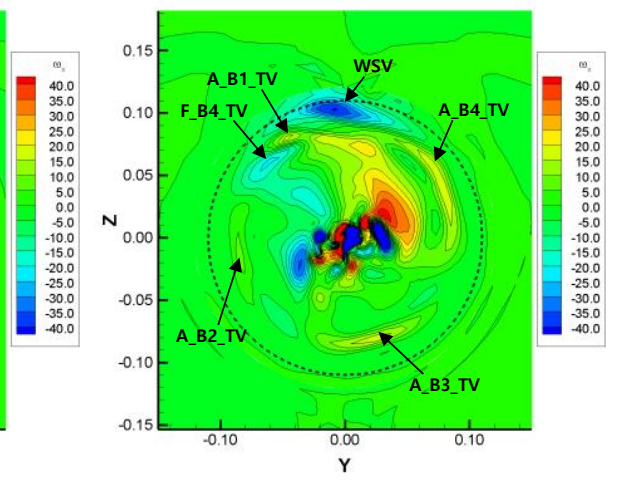

(c) Position C

Fig. 14 Time-averaged velocity contours and vectors (top), instantaneous ( $\theta=0^{\circ}$ ) velocity contours and vectors (middle), and axial vorticity contours (bottom) at positions $\mathrm{A}, \mathrm{B}$, and $\mathrm{C}$ for without-a-rudder condition

The velocity contours and vectors at positions $\mathrm{A}, \mathrm{B}$, and $\mathrm{C}$ for the cases without a rudder are illustrated in Figure 14. The axial velocity of the port side at position A is more accelerated due to the rotational direction of the forward propeller operating in the upward tangential inflow velocity, while the axial velocity of the starboard side at position B is accelerated more due to the rotational direction of the aft propeller operating in the swirling wake of the forward propeller. The axial velocity at position $\mathrm{B}$ is more accelerated overall at position $\mathrm{C}$. In the vorticity contours, a pair of bilge vortex (port/starboard bilge vortex, PBV/SBV) generated from the bilge of hull are observed at the port and starboard sides of position A. The WSV is observed at the top of propeller disk at position A, and it moves to the starboard side at positions $\mathrm{B}$ and $\mathrm{C}$. The tip vortices (F_B3_TV, F_B4_TV) of the forward propeller in the port side are stronger than the others (F_B1_TV, F_B2_TV) in the starboard side and the tip vortices (F_B1_TV, F_B4_TV) in the top side is stronger than the others (F_B2_TV, F_B3_TV) in the bottom side due to the axial and tangential components of the hull wake. On the other hand, the 

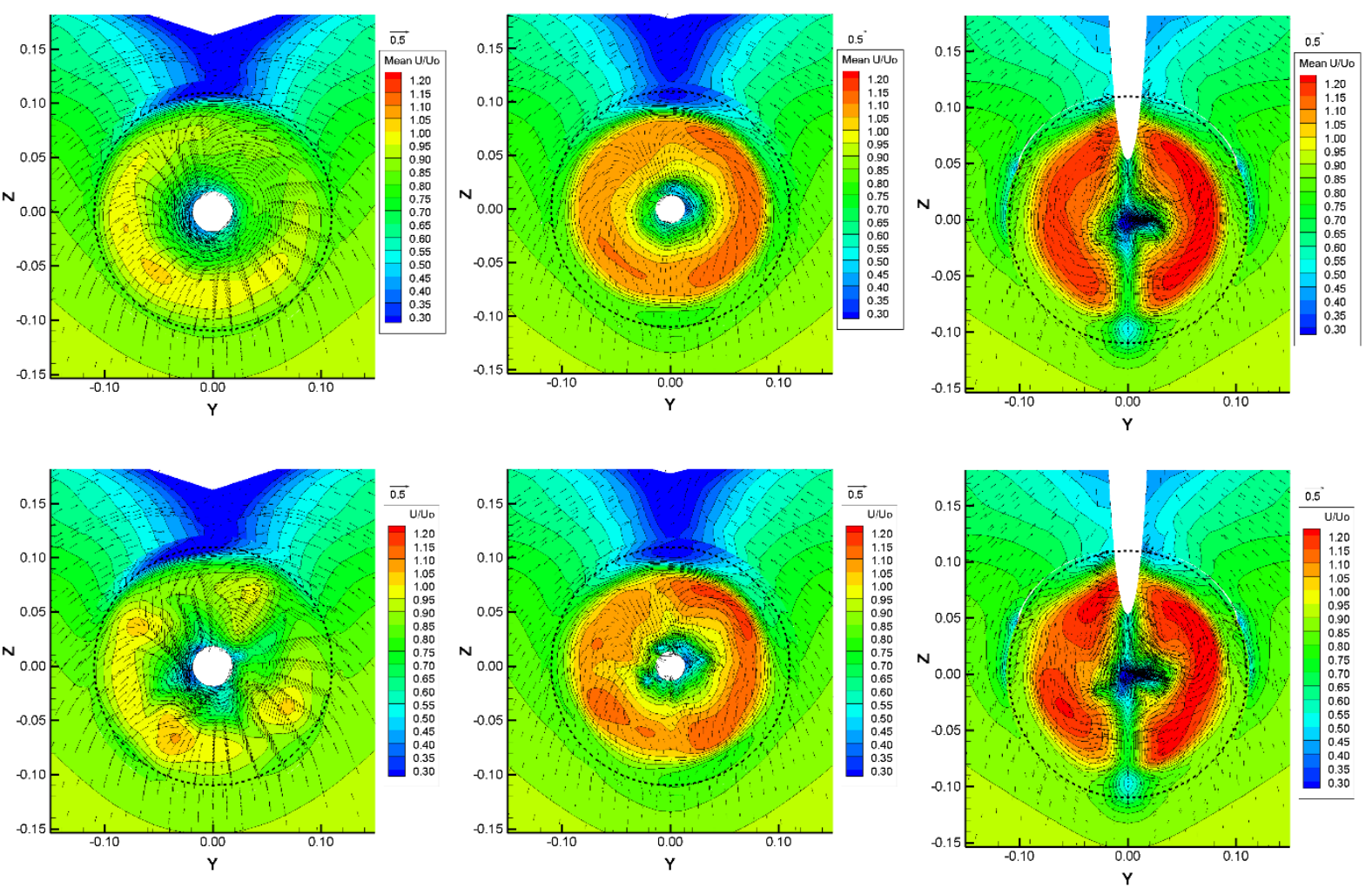

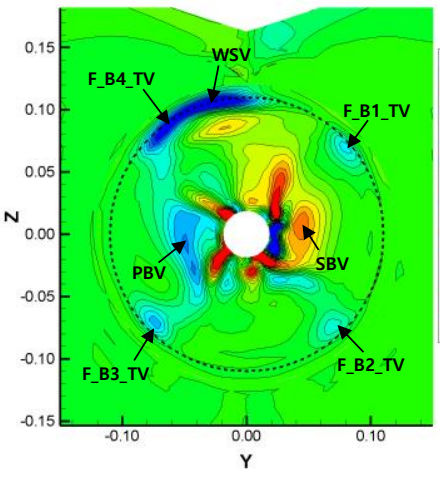

(a) Position A

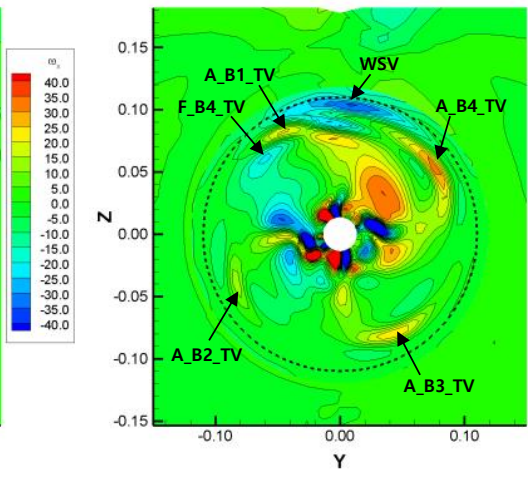

(b) Position B

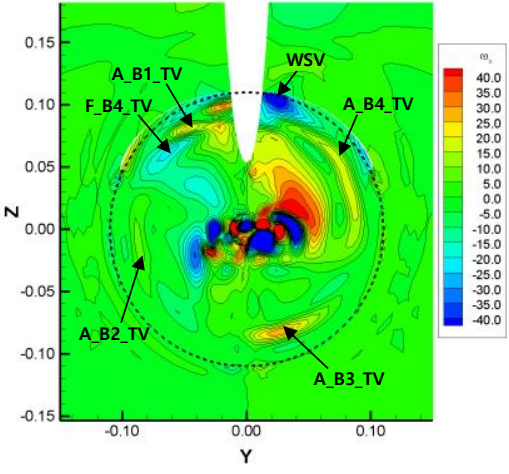

(c) Position C

Fig. 15 Time-averaged velocity contours and vectors (top), instantaneous $\left(\theta=0^{\circ}\right)$ velocity contours and vectors (middle), and axial vorticity contours (bottom) at positions $\mathrm{A}, \mathrm{B}$, and $\mathrm{C}$ for with-a-rudder condition

tip vortex (A_B4_TV) of the aft propeller at the top and port side is stronger than the others due to the rotating swirl of the forward propeller. All vortices of the forward and aft propellers are mitigated at position $\mathrm{C}$.

The velocity contours and vectors at positions $\mathrm{A}, \mathrm{B}$, and $\mathrm{C}$ for the cases with a rudder are illustrated in Figure 15. The wake fields at positions A and B of Figure 14 and Figure 15 are very similar. However, the axial velocity at position $\mathrm{C}$ is almost symmetrical due to the rudder, and the WSV at the propeller top position moves to the starboard side due to the disturbance of the rudder. The tip vortex (A_B3_TV) of the aft propeller at position C is stronger than that of the case without a rudder. 


\section{Conclusions}

In this research, the characteristics of wake evolution for CRP were studied using numerical simulations. The numerical simulations were performed in the propeller open water and self-propulsion conditions. In the self-propulsion conditions, the effect of a rudder was investigated through the cases with and without a rudder.

Flow structure at three transverse planes in propeller downstream were compared with velocity contours and vectors as well as axial vorticity contours. From the propeller open water condition, the reduction of tangential energy loss in CRP was investigated through the interaction of the forward and aft propellers. The interaction between the tip vortices of the forward and aft propellers is not strong because the diameter of the aft propeller is about $89 \%$ of the forward propeller, but the root vortex of the forward propeller disappears owing to the interaction with the aft propeller.

From the self-propulsion condition, the existence of rudder was not significantly affected on the wake field. However, there was obvious effect on increase of thrust and torque due to a rudder. As the effects of the rudder, the axial velocity around the leading edge of rudder was almost symmetrical and the WSV at the propeller top position moved to the starboard side.

The increments of thrust of the forward and aft propellers due to the rudder are about $10.3 \%$ and $3.5 \%$, respectively. And the increments of torque of the forward and aft propellers are about $6.8 \%$ and $4.7 \%$, respectively. As a result, the propulsive efficiency of the forward propeller is increased, whereas that of the aft propeller is decreased. The variation amplitude of thrust and torque of the forward propeller is greater than that of the aft propeller. The dominant frequencies of the variation are the $2^{\text {nd }}$ and $4^{\text {th }}$ order blade frequencies. The amplitude of the $1^{\text {st }}$ order blade frequency for the case with a rudder increases slightly owing to the effect of the rudder.

\section{ACKNOWLEDGEMENTS}

This work was supported by INHA UNIVERSITY Research Grant (INHA-53350).

\section{REFERENCES}

[1] Stella, A., Guj, G., and Di Felice, F., "Propeller wake flowfield analysis by means of LDV phase sampling techniques," Experiments in Fluids, vol. 28, pp. 1-10, 2000. https://doi.org/10.1007/s003480050001.

[2] Felli, M. and Di Felice, F., "Propeller wake analysis in nonuniform inflow by LDV phase sampling techniques," Journal of Marine Science and Technology, vol. 10, pp. 159-172, 2005. https://doi.org/10.1007/s00773-005-0201-6.

[3] Tukker, J., Blok, J. J., Kuiper, G., and Huijsmans, R. H.M., "Wake flow measurements in towing tanks with PIV," 9th International Symposium on Flow Visualization, 2000.

[4] Felli, M., Pereira, F., Calcagno, G., and Di Felice, F., “Application of stereo-PIV: propeller wake analysis in a large circulating water channel," 10th International Symposium on Applications of Laser Techniques to Fluid Mechanics, 2000.

[5] Di Felice, F., Di Florio, D., Felli, M., and Romano, G. P., "Experimental Investigation of the Propeller Wake at Different Loading Conditions by Particle Image Velocimetry," Journal of Ship Research, vol. 48, No. 2, pp. 168-190, 2004.

[6] Paik, B.-G., Kim, J., Park, Y.-H., Kim, K.-S., and Kim, K.-Y., “Analysis of wake behind a rotating using PIV technique in a cavitation tunnel," Ocean Engineering, vol. 34, pp. 594-604, 2007. https://doi.org/10.1016/j.oceaneng.2005.11.022.

[7] Felli, M., Camussi, R., and Di Fellice, F., "Mechanisms of evolution of the propeller wake in the transition and far fields," Journal of Fluid Mechanics, vol. 682, pp. 5-53, 2011. https://doi.org/10.1017/jfm.2011.150. 
[8] Hwang, S., Ahn, H., Lee, Y.-Y., Kim, J., and Van, S.-H., "Flow measurement for KVLCC2 hull form with and without propeller and rudder using stereoscopic PIV in towing tank," 10th International Conference on Hydrodynamics, 2012.

[9] Felli, M., Di Feice, F., and Guj, G., “Analaysis of the propeller wake evolution by pressure and velocity phase measurements," Experiments in Fluids, vol. 41, pp. 441-451, 2016. https://doi.org/10.1007/s00348006-0171-4.

[10] Rhee, S. H. and Joshi, S., "CFD validation for a marine propeller using an unstructured mesh based RANS method," Proceeding of ASME FEDSM'03, 2003. https://doi.org/10.1115/fedsm2003-45397.

[11] Di Felice, F., Felli, M., Liefvendahl, M., and Svennberg, U., "Numerical and experimental analysis of the wake behavior of a generic submarine propeller," First International Symposium on Marine Propulsors, 2009.

[12] Arikan, Y., Doğrul, A., and Çelik, F., "Performance Analysis and Investigation of the Slipstream Flow of Podded Propellers,” Brodogradnja, vol. 63, no. 3, pp. 226-233, 2012.

[13] Wang, X. and Walters, K., "Computational analysis of marine-propeller performance using transitionsensitive turbulence modeling,” Journal of Fluids Engineering, vol. 134, pp. 1-10, 2012. https://doi.org/10.1115/1.4005729.

[14] Baek, D.-G., Yoon, H.-S., Jung, J.-H., Kim, K.-S., and Paik, B.-G., "Effects of the advance ratio on the evolution of a propeller wake," Computers \& Fluids, vol. 118, pp. 32-43, 2015. https://doi.org/10.1016/j.compfluid.2015.06.010.

[15] Kinaci, O. M. and Gokce, M. K., "A computational hydrodynamic analysis of duisburg test case with free surface and propeller,” Brodogradnja, vol. 66, no. 4, pp. 23-38, 2015.

[16] Tsakonas, S., Jacobs, W. R., and Liao, P., "Prediction of steady and unsteady loads and hydrodynamic forces on counterrotating propellers," Journal of Ship Research, vol. 27, no. 3, pp. 197-214, 1983.

[17] Hoshino, T., "Experimental and theoretical analysis of propeller shaft forces on contra-rotating propellers and correlation with full scale data,’ Propellers/Shafting '94 Symposium, 1994.

[18] Paik, K.-J., Seo, S.-B., and Chun, H.-H., "Analysis of contra-rotating propellers in steady flow by a vortex lattice method," Journal of the Korean Society of Ocean Engineers, vol. 14, no. 2, pp.36-43, 2000

[19] Paik, K.-J., Lee, J., Lee, T., Hoshino, T., Park, H.-G., and Seo, J., "Numerical study on the effects of combination of blade number for shaft forces and moments of contra-rotating propeller," Journal of the Society of Naval Architects of Korea, vol. 50, no. 5, pp.282-290, 2013. https://doi.org/10.3744/SNAK.2013.50.5.282.

[20] Paik, K.-J., Hwang, S., Jung, J., Lee, T., Lee, Y.-Y., Ahn, H., and Van, S.-H., "Investigation on the wake evolution of contra-rotating propeller using RANS computation and SPIV measurement," International Journal of Naval Architecture and Ocean Engineering, vol. 7, pp. 595-609, 2015. https://doi.org/10.1515/ijnaoe-2015-0042.

[21] Inukai, Y., "Development of contra-rotating propeller with tip-raked fins," Second International Symposium on Marine Propulsors, Hamburg, Germany, 15-17 June 2011.

[22] Strasberg, M. and Breslin, J. P., "Frequencies of the Alternating Forces due to Interactions of Contrarotating Propellers," Journal of Hydronautics, vol. 10, no. 2, pp. 62-64. 1976.

https://doi.org/10.2514/3.48144.

Submitted: $\quad$ 03.10.2016. Kwang-Jun Pak, kwangjun.paik@inha.ac.kr Department of Naval Architecture and Ocean Engineering,

Accepted: $\quad$ 19.12.2016. Inha University, Incheon 22212, Republic of Korea 